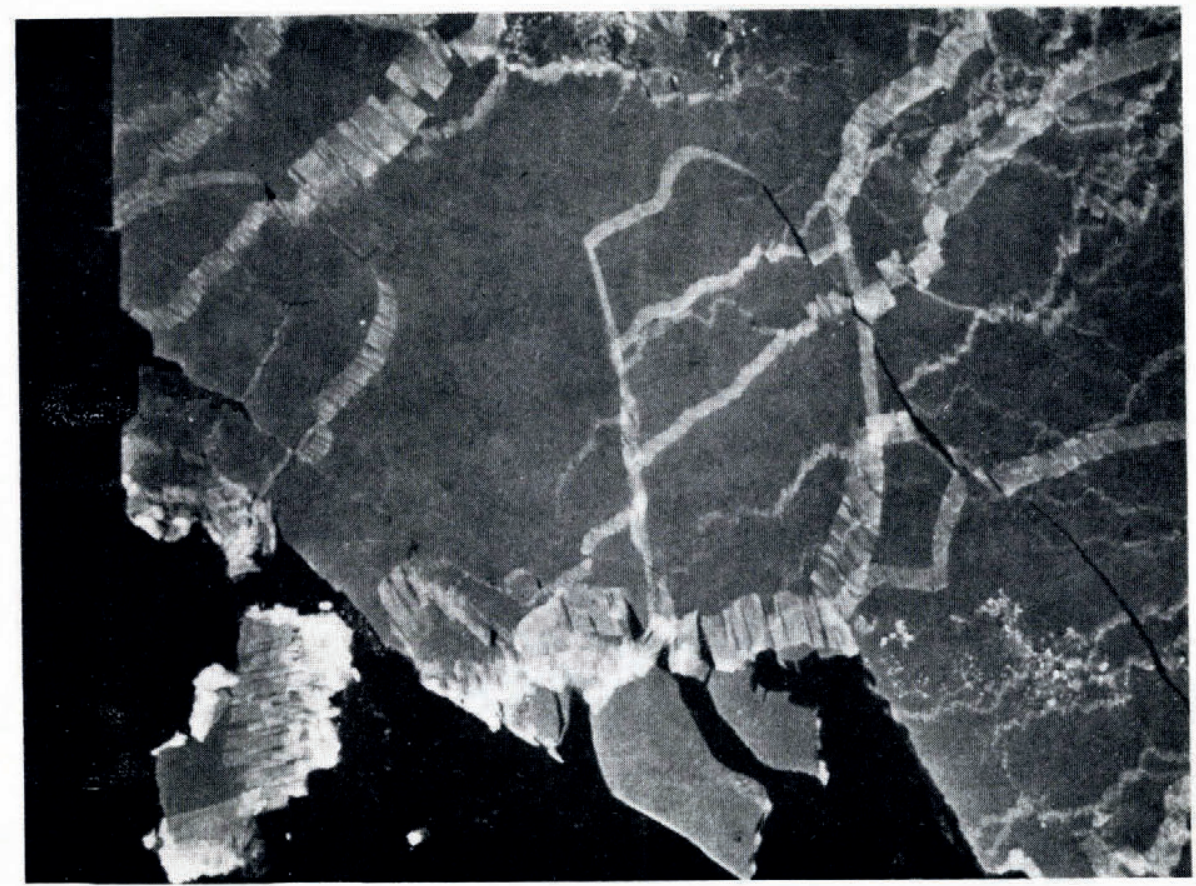

Fig. 3. Thrust structures in very young ice in Hudson Bay, east of Churchill. The lighter colour of the thrusts is due to the double thickness of the ice. The longer thrusts in centre foreground are about $60 \mathrm{~m}$. long. 8 March 1949, altitude about 3,00o ft. (900 m.)

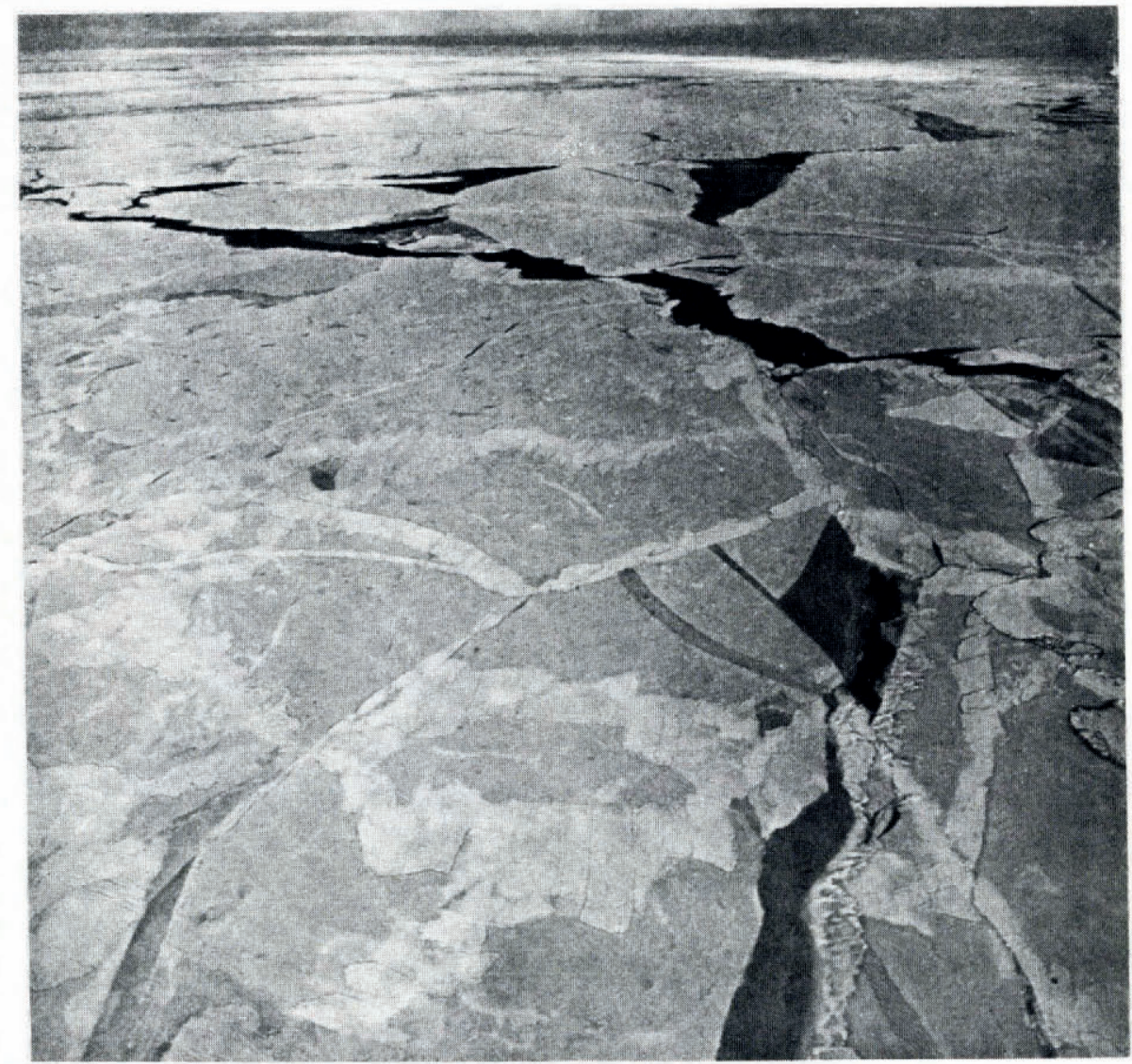

(see p. $727-32)$

4. Thrust structures in slightly thicker ice in northwest Hudson Bay (lat. $62^{\circ} 10^{\prime} \mathcal{N}$., long. $87^{\circ} 20^{\prime}$ W.). 22 November 1949 , altitude about $3,000 \mathrm{ft}$ $(900 \mathrm{~m}$.)

Photographs Royal Canadian Air Force 
iig. 5. North-west Hudson Bay (lat. $61^{\circ} 4^{6} \mathcal{N}$., long. $86^{\circ} 30^{\prime} W$.), showing oblique-angle thrusts and typical rectilinear fractures in young ice. 22 November 194.9 , altitude about $3,000 \mathrm{ft}$. (900 m.)
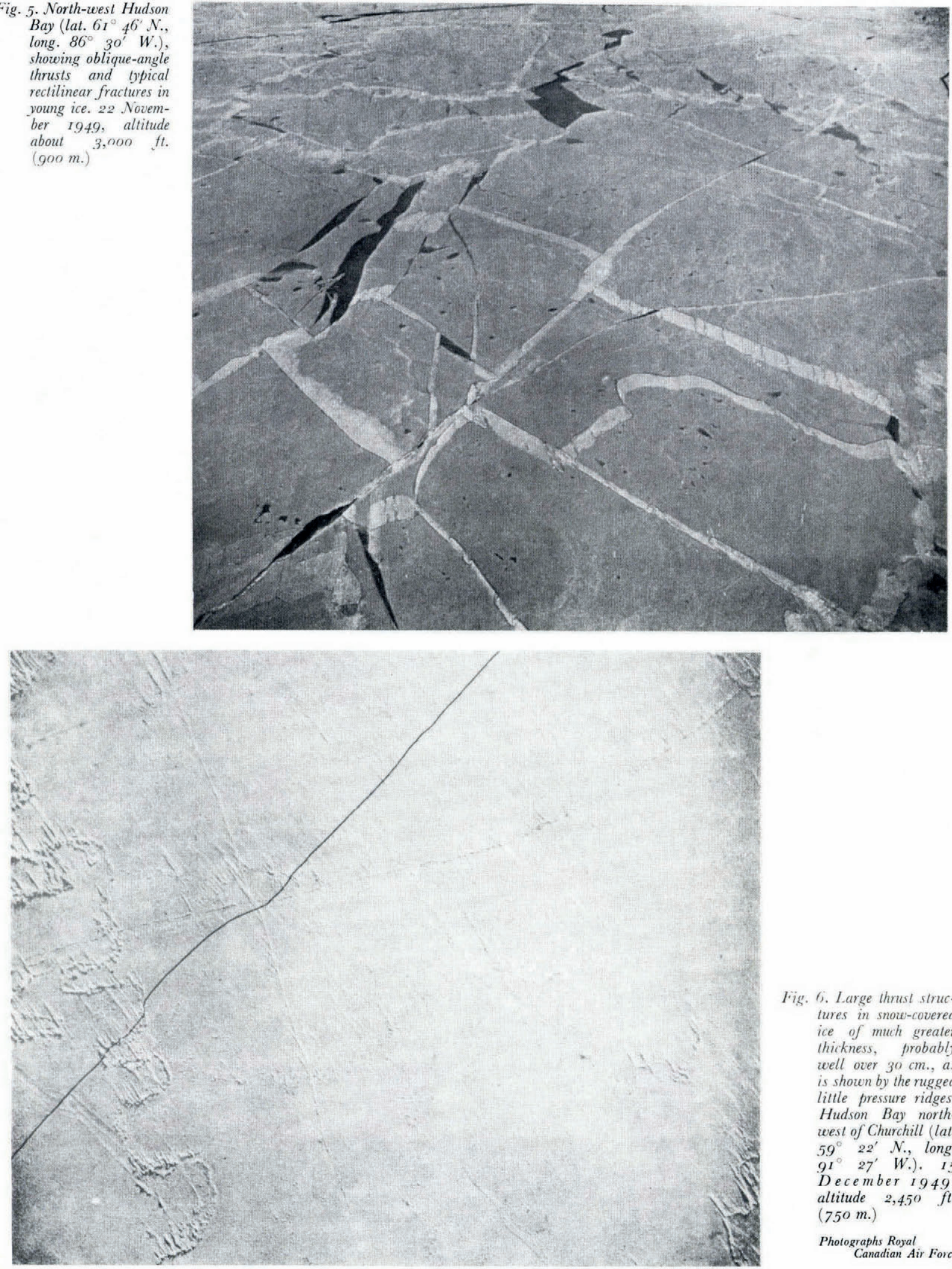

Fig. 6. Large thrusl structures in snow-covered ice of much greater thickness, probably well over $30 \mathrm{~cm}$., as is shown by the rugged little pressure ridges. Hudson Bay northwest of Churchill (lat. $59^{\circ} 22^{\prime} \mathcal{N}$., long. $\begin{array}{lll}9 I^{\circ} & 27^{\prime} & \text { W. }) . \quad 15\end{array}$ December 1949 , altitude $2,450 \mathrm{ft}$. (750 m.)

Photographs Royal Canadian Air Force 


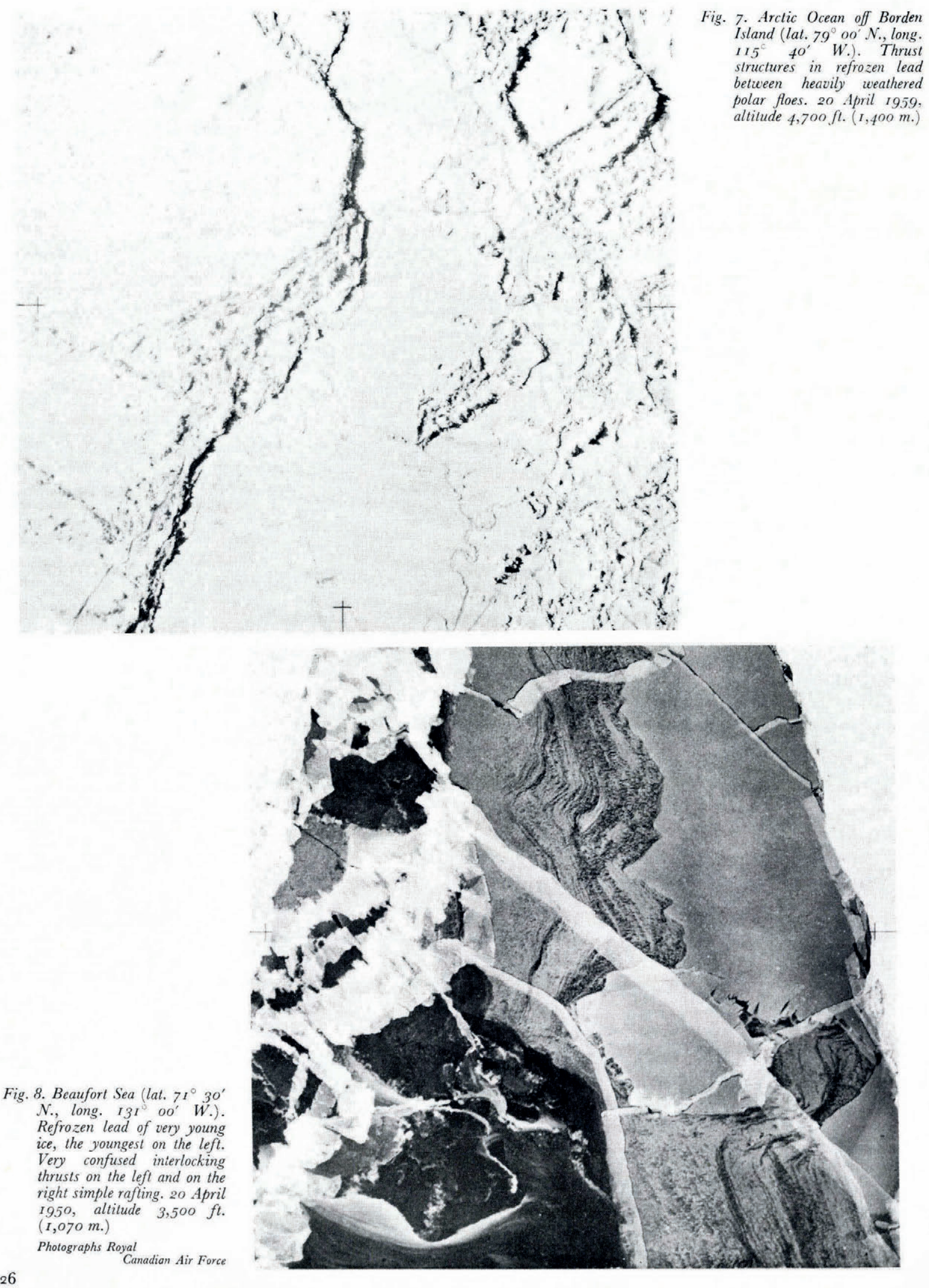




\title{
THRUST STRUCTURES IN YOUNG SEA ICE*
}

\author{
By Moira Dunbar \\ (Geophysics Section, Defence Research Board, Ottawa)
}

\begin{abstract}
Curious interlocking thrust structures, described in the fournal of Glaciolog;, Vol. 3, No. 23, 1958, p. I 73-75, are shown to be a common and typical deformation feature of young sea ice, and a suggestion is put forward as to their formation.
\end{abstract}

RÉsumé. L'auteur montre que de curieuses structures à chevauchement emboîté déjà décrites dans une communication au Journal of Glaciology, Vol. 3, No. 23, 1958, p. 173-75, constituent une déformation typique et commune de la glace de mer nouvelle et elle émet une hypothèse pour expliquer leur formation.

Zusammenfassung. Es wird gezeigt, dass eigentümlich ineinandergreifende Überschiebungsstrukturen, wie sie im Journal of Glaciology, Bd. 3, Nr. 23, 1958, S. 1 73-75 beschrieben sind, ein übliches und typisches Merkmal der Formation jungen Meereises sind, und es wird ein Vorschlag für ihre Entstehung gemacht.

In a short article in the Journal of Glaciology, W. F. Weeks and D. L. Anderson ${ }^{\mathrm{I}}$ described an unusual type of ice structure observed by them at Hopedale, Labrador, and Wolstenholme Fjord, Greenland. The structure consisted of "a series of parallel, rectilinear overthrusts alternating with similarly shaped underthrusts" and was commonly seen in very young ice at the edge of the fast ice. This paper seeks to add to the observations of this type of structure, and to show that it represents a very common and widely distributed fracture pattern in young ice.

Structures of this kind were described by J. F. Holmes and L. V. Worthington ${ }^{2}$ in refrozen leads in the Beaufort Sea. They were also noted in the Gulf of St. Lawrence by W. A. Black, ${ }^{3}$ who uses the phrase "interfingering of young ice" to describe them. There are pictures which show them, but without any comment, in the World Meteorological Organization ice glossary ${ }^{4}$ (unpublished), in Armstrong and Roberts, ${ }^{5}$ and in the Russian glossary of N. I. Yevgenov. ${ }^{6}$ In the latter under "Nilas" (very young elastic ice up to Io $\mathrm{cm}$. thick) is the statement: "Under pressure this ice characteristically rafts in a step-like formation." It is presumed that this rather vague statement may refer to the thrust structures, but no further explanation is given. Burke 7 also shows a photograph and gives a slightly more detailed description of the thrust structures as being typical of "nilas", but again without any explanation. A photograph showing the structures in a lake south of Great Bear Lake was published in the fournal of Glaciology, Vol. 3, No. 24, 1958, p. 291, and the U.S. Navy has photographed the same phenomenon in the Antarctic. I personally have observed the structures from the air in Hudson Bay, and have in my possession numerous photographs of them taken by the Royal Canadian Air Force in Hudson Bay, the Beaufort Sea, M'Clure Strait, and the Arctic Ocean off Borden Island. The Hudson Bay photographs were taken on a series of ice reconnaissance flights which covered the whole length and breadth of the bay, one in March 1949 and four in the winter of $1949-50$, in November, December, January and March; the Beaufort Sea-Arctic Ocean photographs were taken in April i950. The following remarks are based on a study of these photographs, a few of which are shown in Figures 3 to 8.

\section{Fracture Pattern}

The thrust structures are illustrated diagrammatically by both Weeks and Anderson (Fig. I) and by Holmes and Worthington (Fig. 2). It will be seen that there is a considerable

* Paper presented at the First International Symposium on Arctic Geology, Calgary, Alberta, January, r96o, but not published. 
difference between the two diagrams, perhaps partly due to the different conditions in which the phenomenon was observed. Figure I shows a moving sheet of thin ice (dotted) moving in on a stationary fast-ice edge, and shows fracturing limited to the moving ice sheet. Figure 2, based on observations in refrozen leads, shows the meeting of two ice edges, both of which are fractured and interlocked. In photographs it is not always easy to tell the one type from the other, but there is no doubt that both occur; it would seem that the more complex double fracture may be the more common, but this is uncertain.

Both Weeks and Anderson and also Holmes and Worthington refer to the strongly rectilinear form of the overthrusts and to the fact that the direction of thrust is usually perpendicular to the initial or primary break. Weeks and Anderson in particular remark that many of the thrusts are so regular they look as if they had been laid out by a draftsman. This is in general borne out by the photographic examples, but quite a number show considerable obliquity in relation to the primary break, up to about $48^{\circ}$.

\section{Ice THickness}

Weeks and Anderson observed the thrust structures in ice from $2 \mathrm{~cm}$. to $6 \mathrm{~cm}$. in thickness, and are of the opinion that they could not form in ice more than about $12 \mathrm{~cm}$. thick, because it would be too brittle. This is corroborated by Burke. Holmes and Worthington, on the other hand, estimated the ice they saw them in to be "as little as six inches" (15 cm.) and never more than $3 \mathrm{ft}$. (95 $\mathrm{cm}$.) in thickness. They regarded them as danger signals for pilots seeking an ice landing area, signifying thin, weak ice. The air photographs show them in all stages of young ice, from very young black ice (Fig. 3, p. 724) to snow-covered ice which appears to be of considerable thickness (Figs. 6 and 7, p. 725-26). It is likely, however, that the examples seen in thicker ice are merely residual features, formed when the ice was quite thin.

\section{Surface Dimensions}

The horizontal dimensions noted by Weeks and Anderson varied from $10 \mathrm{~cm} . \times \mathrm{I} \mathrm{m}$. to $40 \mathrm{~m} . \times 100 \mathrm{~m}$.; they quote visual observations in the Beaufort Sea of thrusts up to $600 \mathrm{~m}$. They found no correlation between the thickness of the ice and the width or length of the thrusts, but the maximum dimension was usually perpendicular to the initial ice edge. Holmes and Worthington give no details of dimensions. Measurement of photographed thrusts shows a great variety of size, the largest measurable with any degree of accuracy being about $100 \mathrm{~m} . \times 120 \mathrm{~m}$. In the photographs there does seem to be a slight correlation between size and ice thickness, inasmuch as all the very small thrusts photographed are in the thinnest ice, whereas in slightly thicker ice they tend to be larger. However, as it is impossible to say how thick the ice was when the features were formed the slight correlation observed is probably not significant.

The relative dimensions in the photographs also vary very much; in some cases the larger dimension is parallel to the initial break, and not perpendicular to it, as observed by Weeks and Anderson.

\section{Formation}

Unfortunately the process of formation was not observed by Weeks and Anderson, but they put forward an ingenious theory. They suggest that a ragged break forms in a very thin ice sheet, and that when the edges come together again under the influence of an on-shore wind, the forward parts of the ragged edge are lifted by a wave crest over the edge of the fast ice. As the ice is too weak to support its own weight, when the wave crest passes on it tears, 
leaving the forward parts on top of the fast ice and the rest in the water. The intervening parts then slide under the fast ice during the next wave trough. Further pressure forces the thrusts farther and farther on to the fast ice. An interesting point observed by Weeks and

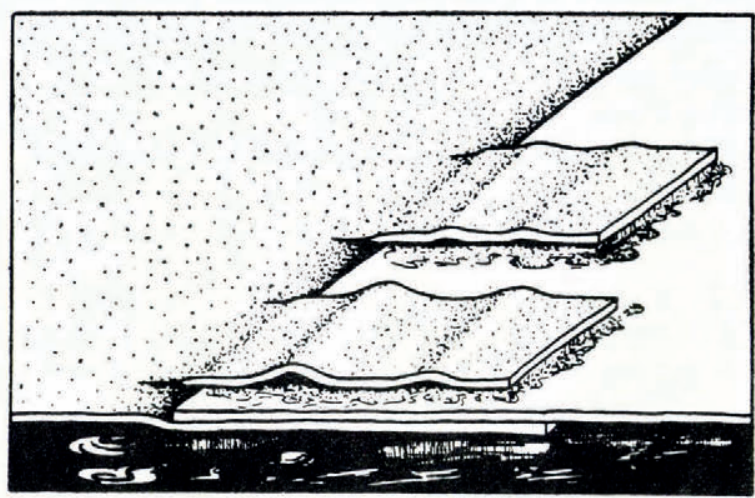

Fig. r. Diagrammatic sketch of thrust structures by Weeks and Anderson

Anderson was that between the overthrusts and the underlying ice there was always a thin film of brine which acted as a lubricant.

This theory does not attempt to explain the type of thrust in which both sheets are fractured, which was not observed by its originators, but it seems likely that wave action may

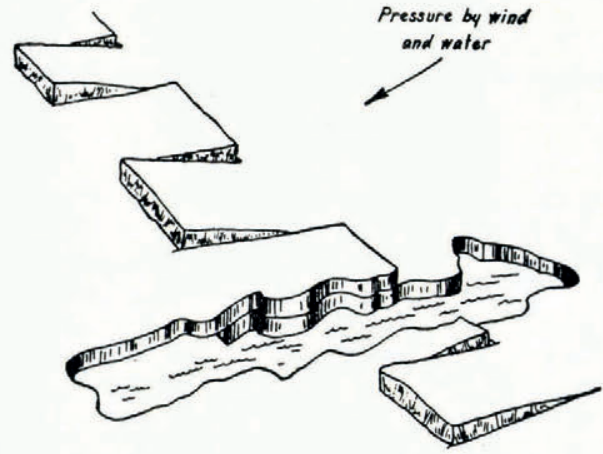

Fig. 2. Diagrammatic sketch by Holmes and Worthington, with section removed to show under side

play a part in the formation of both types. The supposition of a ragged edge to the primary break is somewhat at variance with the evidence of the photographs, which in a great many cases show a very straight, even break; and indeed young ice seems very commonly to break along straight lines (Fig. 5, p. 725). 
This tendency is not in itself hard to account for. Sea ice of the thickness we are considering has little or no structural pattern; the dimensions and arrangement of crystals are random. It therefore seems fairly certain that the fracture patterns found in it must be formed by purely mechanical processes, independent of structure (E. R. Pounder, personal communication). An undisturbed sheet of young ice, when subjected to wave action, will tend to break along parallel straight lines corresponding to the direction of the wave crests. At the same time there will almost certainly be conflicting stresses due to secondary wave direction or to wind, with the result that shear fractures will form at an angle to the first breaks, and in a uniform material without definite lines of structural weakness these fractures will also tend to follow straight lines.

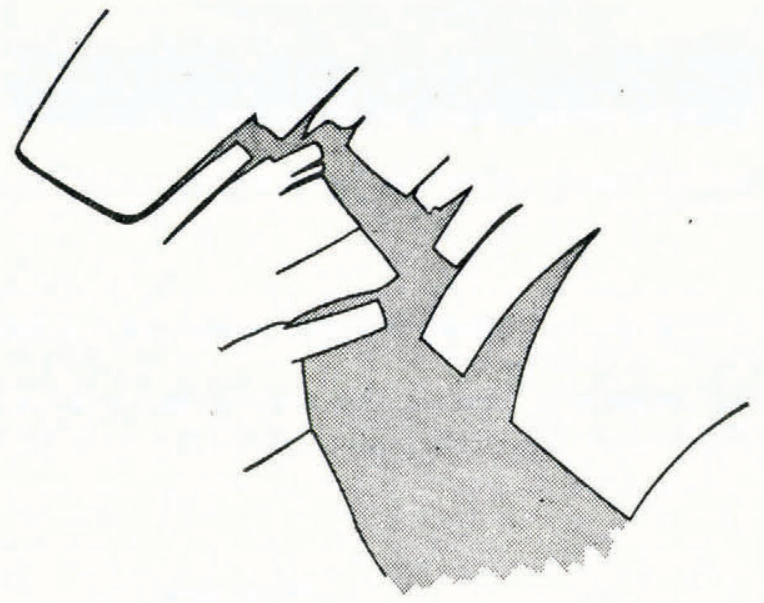

Fig. 9. Enlarged sketch of part of Fig. 8 (lower right)

In the example shown in Figure 5 it appears that the thrusts must have occurred by compression alone, without separation of the sheets between the time of the primary break and the rafting; the interlocking of the various pieces is too complex for it to have been otherwise. In other cases, as in a lead opening and closing, it is clear that separation must occur. An interesting feature appears in the lower right-hand of Figure 8 (p. 726), a rough enlarged sketch of which is shown in Figure 9. The white area represents young grey ice, and the shaded area newer ice. It is clear that this is either ( $I$ ) a former thrust feature that has re-separated; or (2) an incipient thrust feature, the formation of which has been inhibited by the freezing of the intervening water or merely by the relative movement of the two sides of the fracture. If it is the latter, it suggests that the secondary breaks may in at least some cases form first, and not at the actual time of impact between the two ice sheets. A similar feature may be seen in the lower right-hand corner of Figure 4, on the right side of the refrozen lead. Here secondary breaks have formed but interlocking has not taken place; the young black ice, complete with secondary breaks, has simply ridden up over the grey ice. But whether they form before or during rafting, and whether the two sides of the "fault" have or have not been separated and brought together again, the difficulty is not so much to 
explain the secondary breaks, which seem to fit into almost any hypothesis, but to account for the interlocking, and it would appear that wave action remains the most likely mechanism.

Weeks and Anderson noted that the primary break in the thrust structures was usually at right angles to the wind direction at the time of formation of the thrusts. Waves, on the other hand, frequently move at an angle to the wind direction, and it is possible that the thrust structures may form in conditions where the waves approach the primary break obliquely. This is illustrated in Figure ro. The line C-D represents a section along the fault

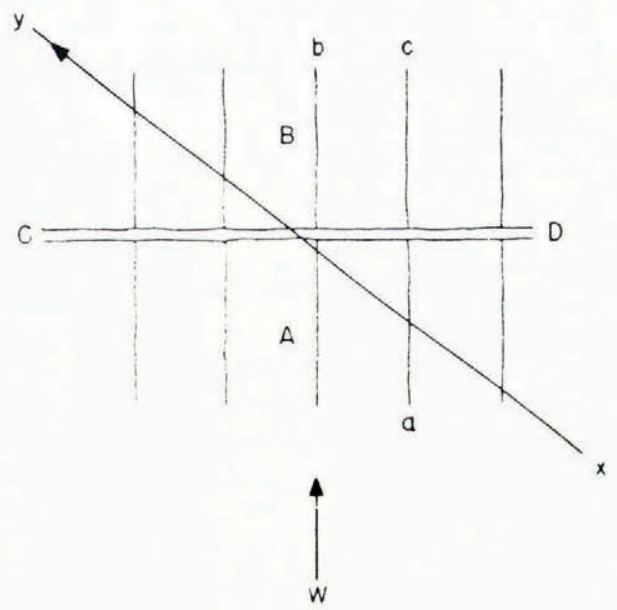

Fig. 10

line between ice sheets $\mathrm{A}$ and $\mathrm{B}$, which are subjected to compression along the axis of wind direction $\mathrm{W}$, with waves approaching obliquely from the right along the line $x-y$ (the exact angle of obliquity will not affect the process). As the rising crest of a wave reaches point $\mathrm{D}$ it will lift the corner of ice sheet $\mathrm{A}$ over ice sheet $\mathrm{B}$ at that point. As the crest passes, the ice of sheet A will be lifted out of the water and a secondary break $a$ will be formed as suggested by Weeks and Anderson, because the ice is too weak to support its own weight; in the trough the relative positions of the ice sheets will be reversed, so that the next section of $\mathrm{A}$ will pass under $\mathrm{B}$, and so on. Break $b$ will be formed by the lifting of sheet $\mathrm{B}$, and at the same time break $c$ will form as a result of the conflicting stresses of the rising of sheet B and the downward pressure of sheet A on top of it. The width between the secondary breaks will depend on the wave length and angle of obliquity of the waves at the time of formation, and will bear no relation to the ice thickness; this is in agreement with the observations of Weeks and Anderson. Thus the more confused the wave pattern the more irregular and apparently haphazard will be the width of the thrusts; a simple regular wave pattern will produce symmetrical thrust patterns.

MS. received I7 March 1960

\section{REFERENCES}

I. Weeks, W. F., and Anderson, D. L. Sea ice thrust structures. Fournal of Glaciology, Vol. 3, No. 23, 1958, p. $173-75$.

2. Holmes, J. F., and Worthington, L. V. Oceanographic studies on project Skijump II. Woods Hole Oceanographic Institution, Technical Report, Ref. No. 53-23, 1953. 
3. Black, W. A. An illustrated glossary of ice types in the Gulf of St. Lawrence. Ottawa, Department of Mines and Technical Surveys, Geographical Branch, 1957. (Miscellaneous Papers Series. Geographical Paper No. ir.) 4. World Meteorological Organization. Illustration of the international ice nomenclature. Hamburg, Fotohaus Friedrich Kunze, 1957.

5. Armstrong, T., and Roberts, B. Illustrated ice glossary. Polar Record, Vol. 8, No. 52, 1956, p. 4-12.

6. Yevgenov, N. I. Al'bom ledovykh obrazovaniy na moryakh [Album of ice formations found at sea]. Leningrad, Gidrometeorologicheskoye Izdatel'stvo [Hydrological and Meteorological Publishing House], 1955.

7. Burke, A. K. Morskiye l'dy [Sea ice]. Leningrad, Moscow, Izdatel'stvo Glavsevmorputi [Publishing House of the Chief Administration of the Northern Sea Route], 1940. [Translated at the Stefansson Library, 1947.] 